\section{Raquitismo e Osteomalacia}

\section{RESUMO}

Raquitismo e osteomalacia são defeitos da mineralização óssea. 0 raquitismo é caracterizado por anormalidades na formação na placa epifisária de crescimento, com áreas não mineralizadas, desorganização da arquitetura celular e retardo na maturação óssea. A osteomalacia é caracterizada pela deficiente mineralização da matriz osteóide do osso cortical e trabecular com acúmulo do tecido osteóide pouco mineralizado. São processos que, em geral, ocorrem associados. Após o final do crescimento, com o fechamento da cartilagem epifisária, apenas a osteomalacia permanece. A falha do processo de mineralização tem como uma das principais causas a inadequada concentração extracelular de cálcio e fósforo, os dois principais componentes minerais do osso, e a falta ou comprometimento da ação dos elementos responsáveis pela sua absorção, particularmente a vitamina $D$. As principais manifestações clínicas como as deformidades ósseas e o atraso no crescimento, são semelhantes nos diferentes tipos de raquitismo e osteomalacia existem características que são específicas. As causas são adquiridas ou hereditárias e os recentes avanços em biologia molecular permitem a identificação dos genes envolvidos e das mutações. Essa discussão inclui os principais tipos da patologia. (Arq Bras Endocrinol Metab 1999; 43/6: 457-466)

Unitermos: Raquitismo; Osteomalacia: Vitamina D: Hipofosfatemia

\section{ABSTRACT}

Rickets and osteomalacia are bone mineralization disorders. Rickets in children occurs due to abnormalities in bone formation at the epiphyseal growth plate and results in defective bone modelling. The growth plate is involved in a process characterized by defective calcification of cartilage, delayed maturation and disorganization of the architecture of the cartilage cells. In osteomalacia there is a failure to mineralize the osteoid organic matrix of bone. This defect results in excessive accumulation of osteoid throughout the skeleton. There is usually some decrease in bone density. Therefore, rickets occurs during growth in children and osteomalacia presents in adults. The mineralization of bone depends on availability and appropriate regulation of inorganic phosphate and calcium, that is made by vitamin $D$. The two components form a major part of hydroxyapatite, the mineral part of bone. Depletion of phosphate or calcium with abnormally low concentrations in extracellular fluid, results in rickets and osteomalacia. Although the clinical manifestations vary to some extend depending upon the underlying disorder, they are mainly related to skeletal deformity, and disturbances in growth. A number of different hereditary or acquired disorders are associated with the mechanism of defective mineralization. Recent advances in molecular genetics are permitting the identification of genes involved in human diseases from their chromossomal location. The ensuing discussion includes major types of rickets and osteomalacia. (Arq Bras Endocrinol Metab 1999; 43/6: 457-466)
Serviço de Endocrinologia, Unidade de Doenças Ósteo-Metabólicas e Laboratório de Investigação Médica25 (LIM /25) do Hospital das

Clinicas da Faculdade de Medicina da Universidade de São Panlo (HC/FMUSP), SP

Keywords: Rickets; Osteomalacia; Vitamin D; Hypophosphatemia 
O RAQUITISMO É UMA DOENÇA ÓSSEA caracterizada pela diminuição da mineralização da placa epifisária de crescimento e a osteomalacia é caracterizada pela diminuição da mineralização do osso cortical e trabecular, com acúmulo de tecido osteóide não mineralizado ou pouco mineralizado. São processos que, em geral, ocorrem associados. Após o fechamento da cartilagem epifisária, ao término do crescimento, apenas a osteomalacia permanece $(1,2)$.

A formação e o crescimento ósseo dependem da produção da matriz óssea, composta principalmente por colágeno, e de sua mineralização através da deposição dos cristais de hidroxiapatita, compostos basicamente de cálcio e fósforo. A falha do processo de mineralização tem como uma das principais causas, a inadequada concentração extracelular desses íons, e a falta ou comprometimento da ação dos elementos responsáveis por sua absorçăo, particularmente a vitatmina $\mathrm{D}(3,4)$.

A vitamina D no organismo é proveniente da dieta e, principalmente, da sua síntese na pele a partir da conversão do 7-dihidrocolesterol, sob a ação do calor e dos raios ultravioleta. Circula ligada à proteina (DBP) e 2 enzimas citocromo P450 mitocondriais participam de sua bioativação. No figado, a 25 hidroxilase, cataliza a hidroxilação do $\mathrm{C}_{25}$, produzindo a 25 hidroxi-vitamina $\mathrm{D}(25 \mathrm{OHD})$, que é a forma mais abundante na circulação. Transportada ao rim, é convertida em 1,25 dihidroxi-vitamina $\mathrm{D}\left[1,25(\mathrm{OH})_{2} \mathrm{D}\right]$ pela ação da $1 \alpha$-hidroxilase. Apesar de vários metabólitos serem formados com a participação de outras enzimas, a $1,25(\mathrm{OH})_{2} \mathrm{D}$, ou calcitriol, é o principal metabólito ativo. A atividade da $1 \alpha$-hidroxilase renal é regulada pelo paratormônio (PTH), $\mathrm{Ca}, \mathrm{P}$ e pelo próprio calcitriol $(4,5)$. Ainda no rim, uma $3^{a}$ enzima, a 4450 citocromo mitocondrial-24 hidroxilase, cataliza a 24 hidroxilação da $25 \mathrm{OHD}$ e da $1,25(\mathrm{OH})_{2} \mathrm{D}$, produzindo os metabólitos $24,25(\mathrm{OH})_{2} \mathrm{D}$ e $1,24,25(\mathrm{OH})_{2} \mathrm{D}$, respectivamente $(3,6,7)$. A $1,25(\mathrm{OH})_{2} \mathrm{D}$ liga-se a receptores específicos e ativa a transcrição de vários genes nos órgãos alvo (8-11). O receptor para $1,25(\mathrm{OH})_{2} \mathrm{D}$ (VDR) pertence à superfamília dos receptores nucleares e, normalmente, forma homodímeros, ou heterodímeros principalmente com os receptores do ácido retinóico (RAR) e do ácido 9cis-retinóico (RXR) $(10,12,13)$. Ações não genômicas da $1,25(\mathrm{OH})_{2} \mathrm{D}$ são realizadas através de receptores de membrana com propriedades de ligação hormonal diferentes dos receptores nucleares e citosólicos. Esses receptores são responsáveis pelo estímulo hormonal rápido da absorção intestinal de $\mathrm{Ca}$, denominado transcaltáquia (14). A $1,25(\mathrm{OH})_{2} \mathrm{D}$ promove a absorção de Ca e P no intestino e a reabsorção de $\mathrm{P}$ no túbulo proximal renal. Através do aumento da concentração de $\mathrm{Ca}$ extracelular controla, indiretamente, a secreção de (PTH) e tem ação inibitória direta sobre a sua transcrição gênica nas paratiróides $(8,10,15)$. A redução da calcemia determina o aumento da secreção de PTH, que estimula a reabsorção tubular de Ca, promove a sua mobilização a partir do osso e estimula a formação de $1,25(\mathrm{OH})_{2} \mathrm{D}$. A cartilagem de crescimento contém receptores intracelulares para $\mathrm{I}, 25(\mathrm{OH})_{2} \mathrm{D}$ e $24,25(\mathrm{OH})_{2} \mathrm{D}$ nos condrócitos das zonas proliferativa e hipertrófica, onde promove o aumento da concentração de $\mathrm{Ca}$, estimula a produção das interleucinas $1 \alpha$ el $\beta$ e promovem a proliferação celular $(16,17)$. Vários órgãos possuem receptores para a vitamina $D$, (linfócitos, monócitos, adipócitos, hipófise, ovários, testículos, mamas, próstata, timo, músculo cardíaco) indicando a sua participação em outros processos fisiológicos além da formação óssea $(12,18)$.

Classificação relacionada à concentração de $\mathrm{Ca}, \mathrm{P}$ e vitamina $\mathrm{D}$ :

\section{- Vitamina D}

Redução dos metabólitos circulantes

Exposição insuficiente à luz ultra-violeta

Vitamina D insuficiente na dieta

Síndromes de má absorção

Metabolismo anormal

Hepatopatias crônicas

Insuficiência renal crônica

Acidose sistêmica

Uso de Anticonvulsivantes

\section{Genéticas}

Dependente de vitamina $D$ tipo I: mutações no gene da enzima l $\alpha$ hidroxilase ( $12 \mathrm{q} 13$ ), autossômica recessiva (19-27).

Dependente de vitamina $\mathrm{D}$ tipo II ou Resistente à vitamina D: mutações no gene do receptor da vitamina D (12q 14), autossômica recessiva (28-31). Defeitos da proteína transportadora da vitamina D - DBP (4q) ou do seu receptor (megalina) $(32,33)$.

\section{- Fosfato}

Perda renal: tubulopatias, S. Fanconi, oncogênica (fator humoral fosfatúrico - fosfatonina) (34-36).

Síndromes de má absorção

Medicamentos: antiácidos (hidróxido de alumínio)

\section{Genéticas}

Hipofosfatêmico ligado ao cromossomo X (Xp 22): mutações no gene PEX (37-39).

Hipofosfatemia autossômica recessiva, ou dominante (12p 13) $(36,41)$.

Hipofosfatemia com hipercalciúria $(3,36)$ 
- Cálcio

Baixa ingestão $(1,42)$

Síndromes de má absorção

- Defeitos primários da mineralização

Hereditários: hipofosfatasia autossômica recessiva ou dominante (lp 36) (43-45).

Adquiridos: uso de medicamentos como fluoretos, etidronatos, alumínio, chumbo.

\section{QUADRO CLÍNICO}

Apesar da existência de características específicas, as principais manifestações clínicas são semelhantes nos diferentes tipos de raquitismo e osteomalacia, sendo mais precoces nos casos hereditários. Os primeiros sinais e sintomas podem surgir desde o $l^{O}$ ano de vida e progredir com a idade, principalmente nas regiōes de desenvolvimento mais rápido. Há atraso no fechamento das fontanelas cranianas, no crescimento, e no desenvolvimento motor; fronte olímpica, craniotabes, retardo na erupção dos dentes, que apresentam estrias, maior propensão às infecções e hipoplasia do esmalte. $O$ abaulamento da junção costo-condral determina o aparecimento do sinal conhecido como rosário raquítico. Os ossos longos apresentam extremidades alargadas, encurvamentos, genu varo ou valgo, coxa vara. A coluna vertebral pode apresentar deformidades em "S", cifose, escoliose c acentuação da lordose lombar. As fraturas não são fiequentes. Outros sintomas são hipotonia, fraqueza muscular e dores. Convulsões decorrentes de hipocalcemia, assim como os sinais de Chvostek e Trousseau, são características dos raquitismos dependentes de vitamina $\mathrm{D}$. A alopécia parcial ou total está presente em $2 / 3$ dos pacientes com raquitismo dependente de vitamina $D$ tipo II. As infecções respiratórias são frequentes, principalmente quando a deformidade torácica é acentuada. Os casos adquiridos ocorrem em qualquer faixa etária, e os adultos apresentam osteomalacia com fraqueza muscular, dores e deformidades progressivas em coluna vertebral e nos membros inferiores $(1-3,5)$.

\section{QUADRO RADIOLÓGICO}

O raquitismo é caracterizado por epífises e metáfises alargadas, "em taça", com linhas de mineralização irregulares, sem contornos definidos e atraso na maturação. Nas demais regiões observam-se os sinais de osteomalacia, com osteopenia generalizada, encurvamento dos ossos longos, varismo ou valgismo em membros inferiores, pseudo-fraturas (zonas de Looser) que são mais frequentes em colo de fềmur, omoplata e pubis, fraturas, deformidades na caixa torácica e coluna vertebral: vértebras bicôncavas, cifoescoliose, lordose acentuada. Flutuações na severidade da doença durante o crescimento, resultam no aparecimento de linhas radiodensas, paralelas à metáfise. Nos casos dependentes de vitamin $\mathrm{D}$, com hiperparatiroidismo secundário, há áreas de reabsorção subperiosteal e cistos $(1-3,5)$.

\section{QUADRO HISTOLÓGICO}

O raquitismo é caracterizado por alterações na placa epifisária de crescimento, onde a zona de hipertrofia está alongada e com desorganização da arquitetura das colunas celulares. A calcificação é retardada ou ausente, a vascularização é irregular através de canais defeituosos. A camada esponjosa das metáfises mostra barras de cartilagem não calcificada. O quadro histológico da osteomalacia mostra alterações da mineralização no osso cortical e trabecular, com aumento da espessura osteóide (superior a $15 \mu \mathrm{m}$ ), deficiente marcação da frente de mineralização com tetraciclina, diminuição da velocidade de mineralização (MLT - intervalo de tempo de mineralização - superior a 100 dias). Nos quadros dependentes de vitamina $\mathrm{D}$ há áreas com sinais de ação osteoclástica aumentada $(16,46)$.

\section{O RAQUITISMO HIPOFOSFATÊMICO}

Descrito por Albright em 1937, como uma forma de raquitismo resistente à vitamina $\mathrm{D}$, por esta ser necessária em doses elevadas para o tratamento (1-3,5). No entanto, atualmente, o termo resistente caracteriza o raquitismo dependente de vitamina D tipo II. Formas autossômicas recessiva ou dominante (12p-13) foram descritas, mas o raquitismo hipofosfatêmico com transmissão dominante ligada ao cromossomo $\mathrm{X}$ é o mais comum. O gene responsável pela patologia está localizado em Xp22-1 e foi denominado gene PEX ou PHEX gene regulador do fosfato, com homologia à família das endopeptidases neutras, localizado no cromossomo X. Sua estrutura consiste de 22 exons que codificam uma proteína com 749 aminoácidos. Os membros desta família possuem um domínio amino-terminal intracelular, um único domínio transmembrana e um domínio maior, extracelular, carboxi-terminal, com 10 resíduos de cisteína conservados. Cerca de 31 mutações (missense, nonsense ou deleção) foram descritas até o momento nesse gene, associadas ao raquitismo hipofosfatêmico c 6 casos de polimorfismo (37-40).

Vários genes participam da homeostase do P. Sua reabsorção, na borda em escova do túbulo contornado proximal renal, é feita pelo cotransportador de Na e P 
(NPT2) $(47,48)$, cujo gene codificador está localizado no cromossomo $5(5 \mathrm{q} 35)$. O NPT2 sofre ação inativadora da fosfatonina, um hormônio peptídeo, produzido provavelmente pelos hepatócitos, cuja estrutura molecular não está totalmente identificada (34-36). O transplante de rins de ratos normais para ratos hipofosfatêmicos e, também, a realização de parabiose entre eles, evidenciou a perda de fosfato pelos rins anteriormente normais, caracterizando a existência desse fator humoral fosfatúrico $(49,50)$. A fosfatonina participa também do metabolismo renal da $1,25(\mathrm{OH})_{2} \mathrm{D}$ através da inibição da enzima la-hidroxilase ou do aumento do seu catabolismo pela ação da enzima 24 hidroxilase. Assim, apesar da hipofosfatemia, que é um estímulo importante para a síntese do calcitriol, este se mantém em concentrações "inapropriadamente" normais nesse tipo de raquitismo. O controle dos níveis circulantes de fosfatonina é feito pelo produto protéico do gene PEX, através de inativação proteolítica. Dessa forma, mutações no gene PEX resultam na produção de uma proteína alterada, incapaz de degradar a fosfatonina, dando origem ao quadro clínico e bioquímico do raquitismo hipofosfatêmico (34-36). Há também evidências da associação de anormalidades intrínsicas dos osteoblastos, colaborando com a formação óssea anormal $(36,40)$. Não está definido se a stanniocalcina (51-53) (8p21), hormônio glicoprotéico com capacidade de inibir a absorção intestinal de $\mathrm{Ca}$ e estimular a reabsorção tubular proximal renal de $\mathrm{P}$, participa desse processo ou tem sua função comprometida.

Quadro bioquímico: pela redução da reabsorção tubular de P (RTP) verifica-se aumento da fosfatúria e hipofosfatemia. As concentrações séricas de $\mathrm{Ca}$, PTH e $25 \mathrm{OHD}$ são normais. A $1,25(\mathrm{OH})_{2} \mathrm{D}$ está "inapropriadamente" normal. Os níveis séricos de fosfatase alcalina e osteocalcina, enzimas produzidas pelos osteoblastos, estão elevadas. A calciúria está diminuída ou normal. Mais raros são os casos de hipofosfatemia com hipecalciúria. A concentração urinária de hidroxiprolina, produto do catabolismo do colágeno, está aumentada. O AMPc urinário, reflexo da atividade do PTH, está normal.

$$
R T P=1-\left(\frac{\text { Purinários }}{\text { (creatinina urinária }} \times \frac{\text { creatinina sérica) }}{\text { P sérico }}\right) \times 100, \text { V.R.: }>90 \%,
$$

\section{Raquitismo dependente de vitamina D tipo I}

Chamado por alguns autores de raquitismo pseudodeficiente em vitamina $\mathrm{D}(19,20)$, é determinado por mutações no gene que codifica a enzima $l \alpha$ hiroxilase, responsável pela conversão da $25(\mathrm{OH}) \mathrm{D} \mathrm{cm}$ $1,25(\mathrm{OH})_{2} \mathrm{D}$ no rim. Transmitindo através de herança autossômica recessiva, o gene está no cromossomo 12 (12q14) e sua estrutura consiste de 9 exons que codi- ficam uma proteina com 508 aminoácidos. A análise funcional da proteína $1 \alpha$ hidroxilase mutante revelou que a atividade enzimática está reduzida. Manifesta-se, em geral, no primeiro ano de vida com retardo no desenvolvimento pôndero-estatural, deformidades ósseas e algumas vezes convulsöes devido a hipocalcemia. Os familiares heterozigóticos são fenotipicamente normais (21-27).

Quadro bioquímico: pela redução da síntese de $1,25(\mathrm{OH})_{2} \mathrm{D}$, a absorção intestinal de Ca está diminuída, com consequente hipocalcemia, hipocalciúria e hiperparatiroidismo secundário, o qual determina redução da RTP e hipofosfatemia. A $25 \mathrm{OHD}$ está normal. Os telepeptídcos resultantes do metabolismo do colágeno estão elevados na urina (28).

\section{Raquitismo dependente de vitamina D tipo II}

Também chamado raquitismo hereditário resistente à vitamina $\mathrm{D}$, é uma doença rara autossômica recessiva, decorrente da resistência tecidual à forma ativa da vitamina D $\left[1,25(\mathrm{OH})_{2} \mathrm{D}\right](28-31,55)$ e causada, em geral, por pontos de mutação no gene do receptor da vitamina D (VDR) (56-73). O VDR é uma proteína de aproximadamente $50 \mathrm{kDa}$, pertencente à superfamília dos receptores nucleares que inclui os receptores para os hormônios esteróides, tireoideos, retinóides e receptores órfăos. Têm uma organizaçăo estrutural comum, compreendendo 2 domínios funcionais principais: um de ligação ao hormônio e outro de ligação ao DNA. O domínio de ligação ao DNA apresenta o maior grau de homologia entre os receptores nucleares e tem a conformação de 2 alças ou dedos de zinco, essenciais para a interação com o DNA. O gene que codifica o VDR humano está no cromossomo $12(12 \mathrm{q} 14)$, e sual estrutura consiste da sequência de 9 exons codificadores (74). A maioria das mutações encontradas no gene do VDR humano foi verificada nos exons 2 e 3 que codificam o domínio de ligação ao DNA. Clinicamente os pacientes apresentam as deformidades ósseas anteriormente referidas, convulsões c alopecia.

A Alopecia - Aproximadamente $2 / 3$ desses casos apresentam alopecia parcial ou total. É um dos primeiros sintomas e, algumas vezes, há queda dos cílios e supercílios. Está presente em indivíduos com diferentes tipos de mutação no VDR, diferentes graus de alteração bioquímica e não se restabelece com o tratamento. A causa não está esclarecida. Através de auto-radiografia, foi demonstrada alta afinidade de captação da $\left[{ }^{3} \mathrm{H}\right] 1,25(\mathrm{OH})_{2} \mathrm{D}$ no núcleo da bainha externa da raiz do folículo piloso de roedores, além do que, a epiderme e o folículo piloso contêm a proteína 
ligadora de Ca que é parcialmente dependente da vitamina $\mathrm{D}(75,76)$. Tanto a $1,25(\mathrm{OH})_{2} \mathrm{D}$ quanto o ácido retinóico, cujos receptores dimerizam, participam do crescimento e diferenciação das células epidérmicas, dos pêlos e cabelos. Estudo imunohistoquímico demonstrou que os queratinócitos da bainha externa da raiz do pêlo $c$ os fibroblastos da papila dérmica expressam fortemente o VDR e o RXR-a, com grau de imunorreatividade maior nas fases anagênica $e$ catagênica $(9,76)$. O sistema intacto do VDR é, portanto, importante para a diferenciação do folículo piloso, de maneira independente da homeostase mineral, embora não se conheça exatamente o seu mecanismo efetor.

O exame histológico do couro cabeludo realizado em 3 dos pacientes com alopécia total, acompanhados em nosso serviço, demonstrou ausência de pelos, e rarefação e hipoplasia dos folículos pilosos. A derme, os seus componentes colagênico e elástico e as glândulas sebáceas e sudoríparas estavam normais. A presença de fibrose perifolicular e de infiltrado linfomononuclear não foi significante. Não foram verificadas outras características específicas, cicatriciais ou inflamatórias.

Quadro bioquímico: a concentração sérica de $1,25(\mathrm{OH})_{2} \mathrm{D}$ está bastante elevada, enquianto a calcemia está diminuída, caracterizando o quadro de resistência hormonal. Os níveis séricos de $\mathrm{PTH}$, fosfatase alcalina e osteocalcina estão elevados; a RTP c calciúria estão reduzidas. Os pais, heterozigóticos, podem apresentar níveis séricos de $1,25(\mathrm{OH})_{2} \mathrm{D}$ pouco elevados, indicando um quadro de resistência parcial (72).

\section{OSTEOMALACIA ONCOGÊNICA}

É una sindrome rara, caracterizada pela presença de um tumor, associado à RTP diminuída e à osteomalacia. As alteraçóes bioquímicas e os quadros clínico c histológico revertem com a retirada do tumor, o qual secreta um fator humoral fosfatúrico e inibidor da atividade da enzima la-hidroxilase, com redução da síntese de $1,25(\mathrm{OH})_{2} \mathrm{D}$. Esse fator humoral seria a fosfatonina, ou seja, o mesmo que participa da patogênese do raquitismo hipofosfatêmico, que envolve o gene PEX, previamente analisado. Larga variedade de tumores em ossos e tecidos moles foi encontrada associada à patologia: mesenquimais, angiosarcomas, hemangiomas, condrosarcomas, carcinoma de próstata, schwanoma, osteoblastoma, tumores neuroendócrinos c mistos (1-3,34-36). Muitas vezes o diagnóstico é difícil, pois são pequenos e de crescimento lento, não podendo ser localizados on total- mente removidos. Determinam o aparecimento da osteomalacia, em geral, como doença óssea adquirida na fasc adulta, sendo menos frequente na infầncia. Além do exame físico, a pesquisa envolve todos os exames diagnósticos por imagem: ultrassonográficos, radiológicos e cintilográficos (particularmente com octreotídeo).

Quadro bioquímico: as alterações laboratoriais são semelhantes às do raquitismo hipofosfatêmico, cxceto pela concentração sérica muito reduzida de $1,25(\mathrm{OH})_{2} \mathrm{D}$. A RTP está diminuida com consequente hiperfosfatúria e hipofosfatemia. A concentração sérica de Ca, PTH e 25OHD está normal e a da fosfatase alcalina está elevada. Glicosúria e aminoacidúria, particularmente glicinúria, podem estar presentes.

\section{HIPOFOSFATASIA}

É um tipo raro de raquitismo e osteomalacia, caracterizado pela redução da atividade da fosfatase alcalina tecidual não específica, principalmente em figado, osso e rim. É determinada por mutações no gene que codifica a enzima fosfatase alcalina localizado em lp36 (43-45). Pode se expressar em qualquer fase da vida, inclusive no período intrauterino e perinatal, quando causa redução da mineralização óssea, polihidrâmnio, membros curtos e deformados, podendo ser letal. A forma infantil é transmitida através de herança autossômica recessiva e pode estar associada à hipercalcemia, insuficiência renal e aumento da pressão intracraniana. A forma que se expressa no adulto pode ter transmissão autossômica dominante e os níveis séricos de Ca e P são normais. Não é claro se a doença óssea é devida a um defeito qualitativo na molécula da fosfatase alcalina, somente, ou se há um defeito generalizado na função do osteoblasto. O gene humano da fosfatase alcalina consiste de 12 exons, sendo a proteína codificada pelos exons 2 a 12. Cerca de 20 mutações (missense ou deleções) foram identificadas, comprometendo exons distintos, não sendo possível relacionar o ponto de mutação com a forma da doença. Há 3 hipóteses para explicar o comprometimento da mineralização: incapacidade de concentrar o fosfato inorgânico, acúmulo de pirofosfato inorgânico c a perda das pontes entre as fibras de colágeno e as vesículas da matriz.

Quadro bioquímico: apesar de apresentar quadro clínico, radiológico e histológico semelhante aos demais tipos de raquitismo e osteomalacia, difere quanto as alterações laboratoriais. A concentração sérica da fosfatase alcalina e isoenzimas está reduzida. Os níveis séricos de Ca, $\mathrm{P}, 25 \mathrm{OHD}, 1,25(\mathrm{OH})_{2} \mathrm{D}$ e 
PTH, em geral, encontram-se normais nas formas juvenil e adulta. Hipercalciúria c hipercalcemia podem estar presentes no período perinatal. Os níveis de 3 fosfocomponentes estão aumentados: o piridoxalfosfato sérico e a fosfoetanolamina e pirofosfato inorgânico urinários.

\section{RAQUITISMO E OSTEOMALACIA INDUZIDOS POR ANTICONVULSIVANTES}

Os anticonvulsivantes, principalmente o fenobarbital e a difenil-hidantoina, são potentes indutores da atividade das cnzimas oxidases microssomais hepáticas estimulando a produção de metabólitos inativos da vitamina D. Em animais, a administração crônica de fenobarbital, aumenta a captação microssomal hepática, o metabolismo da vitamina $\mathrm{D}$ e a excreção biliar dos seus metabólitos. In pitro, também é observado o aumento do catabolismo microssomal hepático da vitamina $\mathrm{D}$ e de $1,25(\mathrm{OH})_{2} \mathrm{D}$ em produtos inativos. Há também efeitos diretos sobre o metabolismo mincral ósseo ao nível celular. A difenil-hidantoina inibe o transporte de Ca através das membranas celulares c aumenta o efeito supressivo da calcitonina na mobilização de Ca ósseo. In vitro, inibe a síntese de colágeno pela célula óssea e tem efeito supressivo sobre a atividade osteoblástica e osteoclástica. Histologicamente, observa-se aumento da atividade osteoclástica ( I-3,77,78).

Quadro bioquímico: os pacientes em uso de anticonvulsivantes por tempo prolongado podem apresentar hipocalcemia, hiperparatiroidismo secundário, reduçăo das concentrações de $25 \mathrm{OHD}$ e de $24,25(\mathrm{OH})_{2} \mathrm{D}$. Os níveis de $1,25(\mathrm{OH})_{2} \mathrm{D}$ são normais, ou pouco reduzidos.

\section{ACIDOSE}

A mineralização óssea está comprometida na acidose tubular renal e síndrome de Fanconi pela perda tubular de bicarbonato, $\mathrm{P}, \mathrm{Ca}, \mathrm{Mg}, \mathrm{Na}, \mathrm{K}$, glicose, aminoácidos e proteínas, retenção de íons $\mathrm{H}^{+}$e consequente acidose metabólica, além da interferência química direta da acidose. A acidose tubular renal de origem genética, pode ter transmissão autossômica dominante ou recessiva ou ligada ao cromossomo $\mathrm{X}$. $\mathrm{Na}$ anastomose uretero-sigmóide, a reabsorção intestinal dos íons cloreto e hidrogênio da urina é responsável pela acidose. A síntese de $1,25(\mathrm{OH})_{2} \mathrm{D}$ pode estar comprometida apesar da hipofosfatemia $\mathrm{c}$ da tendência à hipocalcemia (79-81).

\section{ENVELHECIMENTO}

As alterações no metabolismo da vitamina $D$ verificadas com o avanço da idade são atribuídas à redução da capacidade de síntese cutânea, redução da hidroxilação hepática e renal, redução da concentração e função dos receptores intestinais e da absorção intestinal, associada à menor exposição solar e menor ingestão de vitamina $\mathrm{D}(5,11,81)$. Em nosso serviço, o estudo histomorfométrico ósseo através de biópsia de crista ilíaca em pacientes idosos com fratura de colo de fêmur, revelou a presença de osteomalacia em 2 dos 8 indivíduos analizados (82). Salientamos a importância do diagnóstico diferencial com a osteoporose.

Quadro Bioquímico: há redução da concentração sérica de $25 \mathrm{OHD}$ e $1,25(\mathrm{OH})_{2} \mathrm{D}$, com tendência à hipocalcemia, hipocalciúria, hiperparatiroidismo secundário, aumento dos nívcis séricos de fosfatase alcalina e redução da fosfatemia.

\section{ANTIÁCIDOS}

A osteomalacia antiácido induzida, particularmente pelo uso prolongado de hidróxido de alumínio, resulta da formação de complexos com o P da dieta na luz intestinal, comprometendo a absorção de $\mathrm{P}(1-3)$. O alumínio, em si, não se deposita na frente de mineralização em quantidade significante, desde que a função renal esteja normal.

\section{RAQUITISMO E OSTEOMALACIA NUTRICIONAIS}

Não é comum o diagnóstico de raquitismo nutricional por simples deficiência de vitamina $\mathrm{D}$ ou de $\mathrm{Ca}$ em nosso meio. Os casos podem ser subclínicos, com comprometimento apenas do crescimento, limitados a alterações histológicas ou não pesquisados. Todavia, a principal fonte de vitamina $\mathrm{D}$ no organismo é a síntese cutânca pelos raios solares, e não a alimentar. Assemelha-se ao raquitismo dependente de vitamina $D$ tipo I, embora menos acentuado. Pode se instalar em qualquer faixa etária e responde facilmente ao tratamento com doses baixas de vitamina $\mathrm{D}$ (1-3). O nível sérico de 25OHD está reduzido, embora o nível de $\mathrm{l}, 25(\mathrm{OH})_{2} \mathrm{D}$ esteja mantido devido a estimulação da enzima $1 \alpha$-hidroxilase pelo PTH.

\section{TRATAMENTO}

A prevenção do raquitismo e osteomalacia, é feita com a ingestão de alimentos que contenham $\mathrm{Ca}, \mathrm{P}$ e vitamina $\mathrm{D}$ e com a exposição à luz solar. Para pacientes 
cujo quadro se instalou pela falta desses fatores, a correção da dieta e a exposição diária à luz solar, em geral, são suficientes, podendo o tratamento ser auxiliado com lâmpadas de raios ultra-violeta. As quantidades diárias recomendadas na dieta são: vitamina D 400 UI $(10 \mu \mathrm{g})$, Ca 1000 a $1500 \mathrm{mg}$ e P 400 a $1000 \mathrm{mg}$ ( $1-5$ ).

Para pacientes com terapia anti-úlcera ou gastrite por tempo prolongado, recomenda-se a substituição de medicações que contenham hidróxidos de alumínio por omeprazol, ranitidina ou cimetidina.

Nas síndromes de má absorção de gorduras, com deficiência de vitamina $\mathrm{D}$, é indicado o tratamento parenteral com 25OHD, 20 a $30 \mu \mathrm{g}$ ou $1,25(\mathrm{OH})_{2} \mathrm{D}$, na dose de 0,15 a $0,5 \mu \mathrm{g} / \mathrm{d}$, intramuscular (IM) (1-3). Também pode ser utilizado calcife$\mathrm{rol} 100 \mathrm{U} / \mathrm{d} \mathrm{IM}$ oul .500 a $2.000 / \mathrm{d}$ via oral (v.o.) associado ao $\mathrm{Ca} 1,0 \mathrm{~g}$, v.o. (1-3).

A osteomalacia induzida por anticonvulsivantes pode ser previnida com o aumento da exposição ao sol e da ingestão de alimentos com vitamina $D$ e cálcio, podendo ser associado calciferol 2.000 a $6.000 \mathrm{U} / \mathrm{d}$ e Ca $1,0 \mathrm{~g} /$ dia,v.o. $(1,78,79)$.

Nas acidoses, a administração de bicarbonato de sódio 5 a $10 \mathrm{~g} / \mathrm{d}$, v.o., muitas vezes é suficiente para a correção do quadro. Pode ser necessária a administração de calcitriol 0,25 a $1,0 \mu \mathrm{g} / \mathrm{d}$, v.o. $(1,3,80)$.

Não há uma terapia eficiente reconhecida para a hipofosfatasia $(43-45)$.

O tratamento medicamentoso, nos casos hereditários, baseia-se na etiopatogenia do raquitismo e deve ser iniciado precocemente para evitar a progressão das deformidades ósseas. Está indicada a avaliação clínica e a análise laboratorial dos familiares, principalmente crianças. A dose e a frequência de administração de medicações devem ser ajustadas para cada caso, dependendo dos níveis séricos de $\mathrm{Ca}, \mathrm{P}$ e fosfatase alcalina e dos níveis urinários de $\mathrm{Ca}$, basais e evolutivos. Quando são administrados derivados da vitamina $\mathrm{D}$, a avaliação periódica da bioquímica urinária também é importante para previnir a hipercalciúria. O tratamento, em geral, não corrige satisfatoriamente 0 ritmo de crescimento, as deformidades ósseas e as alterações metabólicas.

\section{Raquitismo e osteomalacia hipofosfatêmicos}

$O$ tratamento é feito com $\mathrm{P}$ e vitamina $\mathrm{D}$, a qual promove a absorção intestinal e a reabsorção tubular renal de $\mathrm{P}$, além de previnir a ocorrência do hiperparatiroidismo, secundário à hipocalcemia decorrente da administração de $P$. A dose de P indicada é 30 a 60 $\mathrm{mg} / \mathrm{kg} / \mathrm{d}$ ( $\mathrm{l}$ a $3 \mathrm{~g}$ de P elcmento), v.o., fracionada em 4 vezes. A dose de calcitriol é 0,02 a $0,06 \mu \mathrm{g} / \mathrm{kg} / \mathrm{d}$ e de alfacalcidol ( $1 \alpha \mathrm{OHD}$ ) 0,03 a $0,1 \mu \mathrm{g} / \mathrm{kg} / \mathrm{d}$, v.o., fracionados em 2 vezes ( $1-3)$. De forma alternativa, utiliza-se o calciferol, $20.000 \mathrm{UI} / \mathrm{d}$, v.o. (1-3). O hormônio de crescimento $(\mathrm{GH})$ pode ser associado ao tratamento na dose de 0,05 a $0,08 \mathrm{mg} / \mathrm{kg} / \mathrm{d}$, via subcutânea. O GH promove a RTP e a síntese de $1,25(\mathrm{OH})_{2} \mathrm{D}$ e, a longo prazo, tem efeito positivo sobre o crescimento (84-86).

$\mathrm{Na}$ hipofosfatemia oncogênica é necessária a exérese do tumor. Nos casos em que não foi possível a sua localização ou foi feita apenas a exérese parcial, devese utilizar o esquema terapêutico com $P$ e calcitriol, ou alfacalcidol, exposto anteriormente, ou calcitriol 1,5 a $3,0 \mu \mathrm{g} / \mathrm{d}$, v.o. associado ao P 2,0 a $4,0 \mathrm{~g} / \mathrm{d}$, v.o. (3).

\section{Raquitismo dependente de vitamina D tipo I}

O objetivo do tratamento é a normalização dos níveis séricos de $\mathrm{Ca}$, PTH e fosfatase alcalina, com a administração, preferencialmente, do calcitriol cuja síntese está diminuída. A dose é 0,02 a $0,06 \mu \mathrm{g} / \mathrm{kg} / \mathrm{d}$, v.o., fracionada em 2 vezes. Associa-se o Ca para complementar a dieta $\mathrm{em} 1,5 \mathrm{~g}$ ao dia para crianças e $1,0 \mathrm{~g}$ ao dia para adultos. Outra forma de vitamina $D$ utilizada é o alfacalcidol na dose de 0,03 a $0,1 \mu \mathrm{g} / \mathrm{kg} / \mathrm{d}$, v.o., fracionada em 2 vezes e, menos frequentemente, o calciferol $1.000 \mu \mathrm{g}(40.000 \mathrm{UI})$ a $3.000 \mu \mathrm{g} / \mathrm{d}$, v.o. (1-3).

\section{Raquitismo dependente de vitamina D tipo II}

É uma das formas mais graves da patologia, necessitando doses elevadas de calcitriol, aproximadamente $10 \mu \mathrm{g} / \mathrm{d}$, v.o., fracionadas em 3 ou 4 vezes, associado a calciferol oral $\mathrm{cm}$ dose de até $600.000 \mathrm{UI} / \mathrm{d}$ e Ca 2,0 a $3,0 \mathrm{~g} / \mathrm{d}$, v.o. (3-5). Nas crises convulsivas de causa hipocalcêmica administra-se gluconato de Ca $10 \%$, endovenoso. A infusão endovenosa contínua de $\mathrm{Ca}$, por tempo prolongado, já foi utilizada em alguns casos e, apesar do desconforto e da necessidade de internação, foi eficiente, determinando a remissão raquitismo (87-89). Remissão da doença também foi verificada em um caso tratado com $1 \alpha$ OHD $(90,91)$.

\section{REFERÊNCIAS}

1. Goldring SR, Krane SM. Disorders of Calcification; Osteomalacia and Rickets. In: De Groot LJ. Endocrinology. Philadelphia. WB Saunders, 1989: 1 165-87.

2. Frame B, Parfitt AM. Osteomalacia: current concepts. Ann Intern Med 1978:89:966-82.

3. Termine JD, Robey PG. Bone matrix proteins and the mineralization process. In: Favus MJ. Primer on the metabolic bone diseases and disorders of mineral metabolism. Philadelphia, Lippincott-Raven, 1996;24-8.

4. Compreehensive Endocrinology. Endocrinology of cal- 
cium metabolism. Ed. JA Parsons, New York, Raven Press, 1982

5. Holik MF, Adams JS. Vitamin D metabolism and biological function. In Avioli LV \& Krane SM. Metabolic bone disease. Philadelphia, WB Saunders Company, 1990; 123-64.

6. Labuda $M$, Lemieux N, Tihy F, Prinster C, Glorieux FH. Human 25-hydroxyvitamin D 24-hydroxylase cytochrome) 450 subunit maps to a different chromosomal location than of pseudovitamin D- deficient rickets. J Bonc Mineral Res 1993:8:1397-406.

7. Ohyama $Y$, Okuda K. Isolation and characterization of a cytochocrome P-450 from rat kidney mitochondria that catalyzes the 24-hydroxylation of 25-hydroxyvitamin $D_{3}$ J Biological Chemitry 1991;266:8690-5.

8. Haussler MR, Whitfield GK, Haussler CA, Hsieh JC, Thompson PD, Selznick SH, et al. The nuclear vitamin D receptor: biological and molecular regulatory properties revealed. J Bone Min Res 1998; 13:325-49.

9. Pillai S, Bikle DD, Elias PM. I,25 dihydroxyvitamin D production and receptor binding in human keratinocytes varies with differentiation. J Biol. Chem 1988:263:5390-5.

10. Jameson JL. Steroid/thyroid hormone receptors. Syllabus 1996 - Introduction to Molecular \& Cellular Research: 33-43.

11. Marcus R, Feldman D, Kelsey J. Osteoporosis. San Diego, CA, Academic Press. 1996. I373 p.

12. Bouilion R, Okamura WH, Norman AW. Structure-function relationships in the vitamin $D$ endocrine system. Endocr Rev 1995; 76:200-57.

13. Glass CK. Differential recognition of target genes by nuclea receptor monomers, dimers and heterodimers. Endocr Rev 1994: 15:39 1-403.

14. Nemere I, Schwartz Z, Pedrozo H, Sylvia VL, Dean DD, Boyan BD. Identification of a membrane receptor for 1 , 25-dihydroxyvitamin $\mathrm{D}_{3}$ which mediates rapid activation of protein kinase C. J Bone Min Res 1998; 13:1353-9.

15. Bilezekian JP, Raisz LG, Rodan GA. Principles of Bone Biology. San Diego, CA, Academic Press. 1996. 1398 p.

16. Jannotti JP. Growth plate physiology and pathology. Ortophedic Clinics of North America, 1990:21:1-17.

17. Dean DD. Schwartz Z, Muniz OE, Arsenis $\mathrm{CH}$, Boyan BD Howell DS. Interleukin- $1 a$ and $b$ in growth $P$ late cartilage are regulated by vitamin D metabolites in vivo. J Bone Min Res 1997; 12:1560-9.

18. Berger V, Wilson P, Mcclelland RA, Colston K, Haussler MR, Pike JW, et al. Immunocytochemical detection of 1,25 dihydroxyvitamin $D$ receptors in normal human tissues. J Clin Endocrinol Metab, 1988;67:607-13.

19. Kato S, Yanagiwasa J, Murayama A, Kitanaka S, Takeyama K. The Importance of 25-hydrixyvitamin D3 1 alphahydroxylase gene in vitamin D-dependent rickets. Curr Pin Nephrol Hypertens 1998;7:377-83

20. Glorieux FH. St-Arnaud R. Molecular cloning of (25-HO D) - I alpha-hydroxylase: an approach to the understunciing of vitamin D pseudo-deficiency. Recent Prog Horm Res 1998:53P:341-9, discussion 350 .

21. Fu GK. Portale AA. Miller WL. Complete Structure of the Human Gene for the vitamin D 1 alpha-hydroxylase,
P450c lalpha. DNA Cell Biol 1997; 12:1499-507.

22. Yoshida T, Monkawa T, Tenenhose HS, Goodyer P, Shinki $T$. Suda $T$, et al. Two novel 1-hydroxylase mutations in French-Canadians with vitamin $D$ dependency rickets type I. Kidney Int 1998;63:1694-702.

23. Kitanaka S, Takeyama K, Murayama A, Sato T, Okumura $K$. Nogami $M$, et al. Inactivating mutations in the 25hydroxyvitamin D3 lalpha-hydroxylase gene in patients with pseudovitamin D-deficiency rickets (see comments). N Engl J Med 1998:338:653-61.

24. Monkawa T, Yoshida T, Wakino S, Shinki T. Anazawa H. Deluca HF, ef al. Molecular Cloning of CDNA and Genomic DNA for human 25-hydroxyvitamin D\# I alpha-hydroxylase. Biochem Biophys Res Commun 1997;239:527-33

25. Arnaud RST, Messerlian S, Moir JM. Omdahl JL, Glorieux $\mathrm{FH}$. The 25-hydroxyvitamin D 1 alpha-hydroxylase gene maps to the pseudovitamin D-deficiency rickets (PDDR) disease locus. J Bone Miner Res 1997:12:1552-9.

26. Fu GK, Lin D, Zhang MYH, Bikle DD, Shackleton CHL, Miller WL, et al. Cloning of Human 25-Hydroxyvitamin D-1aHydroxylase and Mutations Causing Vitamin D-Dependent Rickets Type 1. Molecular Endocrinology 1997:1 1:1961-70.

27. Fraser D, Kooh SW, Kind HP. An inborn error of vitamin-D metabolism involving defective converion of 25-hydroxyvitamin D to 1a, 25-dihydroxy-vitamin D. N Engl J Med 1973:289:817-20.

28. Rosen JF, Fleischman AR, Finberg L, Hamstra A, Deluca $H F$. Rickets with alopecia: an inborn error of vitamin $D$ metabolism. J Pediatrics 1979:94:729-35.

29. Brooks MH, Bell NH, Love L, Stern PH, Orfei E, Queener SF, et al. Vitamin-D dependent rickets type II: resistance of target organs to 1,25-dihydroxyvitamin D. N Engl J Med 1978;98:996-9.

30. Marx SJ, Spiegel AM, Brown EM, Gardner DG. Downs RW. Attie $M$, et al. A familial syndrome of decrease in sensitivity to 1,25-dihydroxyvitamin D. J Clin Endocrinol Metab $1978: 47: 7303-10$.

31. Tsuchiya $Y$, Nobutake M, Cho H, Kumagai M, Yasaka $A$, Suda $T$, et al. An unusual form of vitamin $D$ dependent rickets in a child: alopecia and marked end-organ hiposensitivity to biologically active vitamin D. J Clin Endocrinol Metab 1980:51:685-90.

32. Justin S, Bushinsky DA. Mineral metabolism prepares for the new millenium. Curr Opin Nephrol Hypertens 1999:8:405.

33. .Liu W, Yu WR, Carling T, Juhlin C, Rastad J, Ridefelt P, ef al. Regulation of gp $330 /$ megalin expression by vitamins $A$ and D. Eur J Clin Invest 1999:28:100-7.

34. Kumar R. Phosphatanin - a new phosphaturetic hormone? (Lessons from fumour-induced osteomalacia and X-linked hypophosphataemia). Nephrol Dial Transplant 1997:12:17-3

35. Nelson AE, Robinson BG, Mason RS. Oncogenic osteomalacia: is there a new phosphate regulating hormone? Clin Endocrinol 1997:47:635-42.

36. Rowe PSN. Molecular biology of hypophosphatemic rickets and oncogenic osteomalacia. Hum Genet 1994:94:457-67. 
37. Francis F, Rowe PSN, Econs MJ, Oudet C, Strom TM. A gene (PEX) with homologies to endopeptides is mutated in patients with X-linked hypophosphatemic rickets. Nature Genetics 1995:7 1:130-6.

38. Holm IA, Huang $X$, Kunkel LM. Mutational analysis of the PEX gene in patients with $X$-linked hypophosphatemic rickets. Am J Hum Genet 1997:60:790-7.

39. Dixon PH, Christie PT, Wooding C, Trump D, Grieff $M$, Holm I, et al. Mutational analysis of PHEX gene in X-linked hypophosphatemia. J Clin Endocrinol Metabol 1998:83:3615-23.

40. Rowe PSN. The PEX gene: is role in X-linked rickets, osteomalacia, and bone mineral metabolism. Exp Nephrol $1997 ; 5: 355-63$

41. Econs MJ, Mcenery PT, Lennon F, Speer MC. Autosomal dominant hypophosphatemic rickets is linked to chromosome 12p13. J Clin Invest 1997: 100:2653-7.

42. Sharp CA, Oginni LM, Worsfold M, Oyelami AO. Risteli L, Risteli $J$, et al. Elevated collagen turnover in nigerian children with calcium-deficiency rickets. Calcif Tissue Int $1997 ; 61: 87-94$

43. Ozono K, Yamagata M, Michigami T, Nakajima S, Sakai $N$. Cai $G$, et al. Identification of novel missense mutations (Phe310eu and Gly439Arg) in a neonatal case of hypophosphatasia. J Clin Endocrinol Matabol 1996;81:4458-61.

44. Ramage IJ, Howatson AJ, Beattie TJ. Hypophosphatasia. J Clin Pathol 1996:49:682-4.

45. Cai $G$, Michigami T, Yamamoto T, Yasui $N$. Satomura $K$. Yamagata $M$, et al. Analysis of localization of mutated tissue-nonspecific alkaline phosphatase proteins associated with neonatal hypophosphatasia using green fluorescent protein chimeras. J Clin Endocrinol Metabol $1998 ; 83: 3936-42$.

46. Correa PHS, Leite MOR, Borelli A. Wajchenberg BL. Effect of testosterone on bone mineralization of the hypophosphatemic rat. Acta Endocrinol 1992:126:510-4.

47. Dousa TP. Modulation of renal Na-Pi cotransport by hormones acting via genomic mechanism and by metabolic factors. Kidney International 1996:49:997-1004.

48. Tenenhouse HS. Cellular and molecular mechanisms of renal phosphate transport. J Bone Min Res 1997:12:159-64.

49. Meyer Jr RA, Meyer MH, Gray RW. Parabiosis suggests a humoral factor is involved in $x$-linked hypophosphatemia in mice. J Bone Min Res 1989;4:493-500.

50. Nesbitt T, Coffman TM, Griffiths $R$, Drezner $M$. Crosstransplatation of kidneys in normal and hyp mice. Evidence that the hyp mouse phenotype is unrelated to an intrinsic renal defect. J Clin Invest 1992;89:1453-9.

51. Wagner GF, Vozzolo BL, Jaworski E, Haddad M, Kline RL, Olsen HS, ef al. Human stanniocalcion inhibits renal phosphate excretion in the rat. J Bone Min Res 1997:12:165-77.

52. Madsen KL, Tavernini MM, Yachimec C. Menrick DL, Afonso PJ, Buergin $M$, et al. Stanniocalcin: a novel protein regulating calcium and phosphate transport across mammalian intestine. Americam Physiological Society 1998:G96-G102.

53. Varghese R, Wong CKC, Deol H, Wagner GF, Dimattia
G. Comparative analysis of mammalian stanniocalcin genes. Endocrinology 1998;139:4714-25

54. Broadus AE. Nephrogenous cyclic AMP as a parathyroid functions test. Nephron 1979:23:136-41.

55. Liberman VA, Halabe A, Samuel R, Kauli R. End-organ resistance to 1,25-dihydroxycholecalciferol. Lancet $1980: 8: 504-7$

56. Hirst MA, Hochman HI, Feldman D. Vitamin D resistance and alopecia: a kindred with normal 1,25-dihydroxyvitamin $D$ binding, but decreased receptor affinity for decxyritonucleic acid. J Clin Endocrinol Metab $1985 ; 60: 490-5$

57. Hughes MR, Malloy PJ, Kieback DE, Kesterson RA, Pike $\mathrm{JW}$, Feldman D, et al. Point mutations in the human vitamin $D$ receptor gene associated with hypocalcemic rickets. Science 1988;242:1702-5.

58. Ritchie HH. Hughes MR, Thompson ET, et al. An ochre mutation in the vitamin $D$ receptor gene causes hereditary 1,24-dihydroxyvifamin $D_{3}$ - resistant rickets in three families. Proc Natl Acad Sci USA 1989:86:9783-7.

59. Kristiansson K, Rut AR, Hewison M, O'riordan JLH, Hughes MR. Two mutations in the hormone binding domain of the vitamin $D$ rceptor cause tissue resistance to 1,25 dihydroxyvitamin $D_{3}$. J Clin Invest 1993;92:12-6.

60. Rut AR, Hewison M, Kristjansson K, Luisi B, Hughes MR, O'riordan JLH. Two mutations causing vitamin $D$ resistant rickets: modelling on the basis of steroid hormone receptor DNA-binding domain crystal structures. Clin Endocrinol 1994:41:581-90.

61. Malloy PJ, Weisman Y, Feldman D. Hereditary $1 a, 25$ dihydroxyvitamin $D$ resistant rickets resulting from a mutation in the vitamin $D$ receptordeoxyribonucleic acid-binding domain. J Clin Endocrinol Metab 1994;78:313-6.

62. Malloy PJ, Eccleshall R, Gross C. Maldergen LV. Bouillon R. Feldman D. 1997 Hereditary vitamin D resistant rickets caused by a novel mutation in the vitamin $D$ receptor that results in decreased affinity for hormone and cellular hyporesponsiveness. J Clin Invest 1997:99:297-304.

63. Saijo T, Ito M. Takeda E, Hug AHM. Naito E, Yokota I, ef al. A unique mutation in the vitamin D receptor gene in three Japanese patients with vitamin-D-dependent rickets type II: utility of single-strand conformation polymorphism analysis for heterozygous carrier detection. Am J Hum Genet 1991;49:668-73

64. Hawa NS, Cockerill FJ, Vadher S, Hewison M, Rut AR, Pike $J W$, et al. Identification of a novel mutation in hereditary vitamin $\mathrm{D}$ resistant rickets causing exon skipping. Clin Endocrinol 1996:45:85-92

65. Wiese RJ, Goto H. Prahl JM, Marx SJ, Thomas M, Aqueel AA, et al. Vitamin D-dependency rickets type ll: fruncated vitamin D receptor in three kindreds. Molecular Cell Endocrinol 1993:90:197-201.

66. Sone T, Scott RA. Hughes MR, Malloy PJ, Feldman D. O'malley BW, et al. Mutant vitamin D receptors which confer hereditary resistance to 1,25-dihydroxyvitamin D in humans are transcriptionally inactive in vitro. J Biological Chemistry 1989; v.264, n.34, 20230-4.

67. Whitfield GK, Selznick SH, Haussler CA, Hsieh JC, Galligan $M A$, Jurutka $P W$, et al. Vitamin D receptors from patients with resistance to 1,25-dihydroxyvitamin D3: point muta- 
tions confer reduced transactivation in response to ligand and impaired interaction with the retinoid $X$ receptor heterodimeric partner. Molecular Endocrinol 1996; 10(12) 1617-31.

68. Cockerill FJ, Hawa NS, Yousaf N, Hewison M, O'riordan $\mathrm{JLH}$. Farrow SM. Mutations in the vitamin D receptor gene in three kindreds associated with hereditary vitamin D resistant rickets. J Clin Endocrino Metab 1997; 82 , (9). 3156-60.

69. Malloy PJ, Hochberg Z, Tiosano D, Pike JW, Hughes MR, Feldman $D$. The molecular basis of hereditary 1,25-dihydroxyvitamin D3 resistant rickers in seven related families. J Clin Invest, 1990; 86, 2071-9.

70. Yagi H, Ozono K, Miyake H, Nagashima K, Kuroume T, Pike JW. A new point mutation in the deoxiribonucleic acid-binding domain of the vitamin $D$ receptor in a kindred with hereditary 1,25-dihydroxyvitamin D-resistant rickets. J Clin Endocrinol Metab 1992; 76(2), 509-12.

71. Lin NUT, Malloy PJ, Sakati N, Al-Ashwal A, Feldman D. A novel mutation in the deoxiribonucleic acid-binding domain of the vitamin $\mathrm{D}$ receptor causes hereditary 1,25-dihydroxyvitamin D - resistant rickets. J Clin Endocrinol Metab 1996; 81 (7) 2564-9.

72. Mechica JB, Leite MOR, Mendonça BB, Frazzatto EST. Borelli $A$, Latronico $A C$. A novel nonsense mutation in the first zinc finger of the vitamin $D$ receptor causing hereditary 1,25-dihydroxyvitamin D3-resistant rickets. J Clin Endocrinol Metab 1997; 82(11), 3892-4.

73. Malloy PJ, Pike JW, Feldman D. The vitamin D receptor and the syndrome of hereditary 1,25-dihydroxyvitamin D-resistant rickets. Endocr Rev 1999; 20(2):156-8.

74. Baker AR, Mcdonnell DP, Hughes M. Crisp TM, Mangeldorf DJ, Haussler MR, et al. Cloning and expression of fulllength CDNA encoding human vitamin $D$ receptor. Proc Natl Acad Sci (USA) 1988; 85: 3294-8.

75. Arase S, Sadamoto Y, Kuwana R, Nakamishi H, Fijie $K$ Takeda $\mathrm{K}$, et al. The effect of $1,25(\mathrm{OH})_{2} \mathrm{D} 3$ on the growth and differentiation of cultured human outer root gheath cells from normal subjects and patients with vitamin Ddependent rickets type II with alopecia. J Dermatol Sci 1991; 2(5): 353-60.

76. Sadamoto Y, Arase S, Kato S, Nakamishi H, Fujie K, Takeda $E$, et al. The effect of $1,25(\mathrm{OH})_{2} \mathrm{D} 3$ on cultured human hair follicle cells from a patient with vitamin Ddependent rickets type II with alopecia. Nippon Hifuka Gakkai Zasshi 1990; 10(2): 221-4.

77. Yokota I, Takeda E, Ito M, Kabashi H, Saijo T, Kureda Y. Clinical and biochemical findings in parents of children with vitamin D - dependents rickets type II. J Inherit Metab Dis $1991 ; 14(2): 237-40$.

78. Rabelink TJ. Brains and bones. Nephrol Dial Transplant $1998 ; 13: 801-2$.

79. Brown AR. Epstein S. Drug and hormone effects on vitu- min U melabolism. In Feldman,D. Vitamin D. San Diego, CA. Academic Press, 1997;797-829.

80. Slatopolsky ES, Brown AJ. Vitamin and renal failure In: Feldman,D. Vitamin D. San Diego, CA. Academic Press, 1997; 849-65.

81. Drezner MK. Clinical disorders of phosphate homeostasis In: Feldman D. Vitamin D. San Diego, CA. Academic Press, 1997; 733-53.

82. Francis RM, Selby PL. Ostemalacia. Baillière's Clinical Endocrinology and Metabolism 1997;11:145-63.

83. Batalha JRF, Jorgetti V. Correa PHS, Arioli EL, Teixeira CS, Leite MRO, et al. Estudo histomorfométrico dinâmico de pacientes com fratura de colo de fêmur. Arq Bras Endocinol Metabol 1992:16:161.

84. Reusz GS, Miltényi $G$, Stubnya $G$, Szabó A, Horváth $C$. Byrd DJ, et al. X-linked hypophosphatemia: effects of treatment with recombinant human growth hormone. Pediatr Nephrol 1997; 1 1:573-7.

85. Seikaly $M G$, Brown $R$, Baum $M$. The effect of recombinant human growth hormone in children with $x$-linked hypophosphatemia. Pediatrics 1997;100:879-84.

86. Patel L, Clayton PE, Brain C. Pelekouda E, Addison GM, Price DA, et al. Acute biochemical effects of growth hormone treatment compared with conventional treatment in familial hypophosphataemic rickets. Clin Endocrinol 1996;44:687-96.

87. Bliziotes M, Yergey AL, Nanes MS, Muenzer J, Begley MG. Vieira NE, ef al. Absent intestinal response to calciferols in hereditary resistance to 1,25 dihydroxyvitamin D: documentation and effectiv therapy with high dose intravenous calcium infusions. J Clin Endocrinol Metab 1988;66:284-300.

88. Weisman Y, Bab I. Gazit D, Spizer Z, Jaffe M, Hochberg Z. Long-term intracaval calcium infusion therapy in endorgan resistance to 1,25-dihydroxyvitamin D. Amer J Med 1987:83:984-90.

89. Takeda E, Yokota I, Kawakami I, Hashimoto T, Kuroda Y, Arase S. Two siblings with vitamin D-dependent rickets type II: no recurrence of rickets for 14 years after cessation of therapy. Eur J Pediatr 1989; 149:54-7.

90. Manandha DS, Sarkawi S. Hunt M.C. Rickets with alopecia remission following a course of 1 -alpha-hidroxyvitamin D3 therapy. Eur J Pediatr 1989: 148:76 1-3.

91. Takeda E, Kuroda Y, Saijo T, Naito E, Kobashi H, Yokota I. ef al. la/hydroxyvitamin D3 treatment of three patients with 1,25-dihydroxyvitamin D-receptor defect rickets and alopecia. Pediatrics 1987;80:97-101.

\section{Endereço para correspondência:}

José B Mechica

Av. Dr. Enéas de Carvalho Aguiar $1558^{\circ}$ Andar - Bloco 03 05403900 São Paulo, SP 